\title{
User Acceptance of Information Technology: A Field Study of an E-Mail System Adoption from the Individual Students' Perspective
}

\section{Mansour Naser ALraja}

Assistant Professor, PhD of Management Information Systems, Management Information Systems Department, College of Commerce and Business Administration, Dhofar University, Salalah state, Sultanate of Oman, Postal Code: 211 - P.O. Box: 2509

Email: malraja@du.edu.om

\section{Doi:10.5901/mjss.2015.v6n6s1p19}

\begin{abstract}
Today, students have adopted information technology in terms of emails through they are conveying their information from one place to another. This study has examined that how a set of constructs shape the information technology adoption. Depending on UTAUT model, the study has tested the effects of five constructs including the computer anxiety, performance expectancy, social influence, effort expectancy, and attitude towards the application and adoption of technology. It helped in examining the usage intention of electronic mail system (Outlook) among potential users. For this purpose, five hypotheses have been developed that were empirically validated using manually administered survey e-mail system at Dhofar University. To analyze the results, multiple linear regression analysis has been used. Data which has been collected from Dhofar university students is used, and the UTAUT model explicated $41 \%$ of the variance in students' intention to use the e-mail system. The study has found that only three out of five constructs (effort expectancy, computer anxiety, and performance expectancy) have considerable effect on usage intentions of e-mail system of the students. Implications, suggestions, and limitations of study are also discussed.
\end{abstract}

Keywords: E-mail system, outlook, information technology adoption, UTAUT, performance expectancy.

\section{Introduction}

Huge investments have been made by organizations, which have focused on information technology (IT). It is due to the fact that organizations are increasingly depending on IT to perform many tasks (Jasperson, Carter, \& Zmud, 2005). There is a positive relation between the large investments in IT and greater efficiency in the organization (Pang et al, 2014). Therefore, in educational sector, the use of IT has become very important (Fichman et al, 2014). It is the major sector which has enhanced the scope of research in IT adoption. Thus, it has become a prominent research stream in the field of information systems (Hess et al, 2014). Several studies on the adoption of IT, which have been implemented outside the Sultanate of Oman, provides an opportunity for new research because of many reasons. Sultanate of Oman is a developing country, and this is one of the major reasons. Additionally, another reason is that the Sultanate of Oman has some extent of good wealth. Moreover, there is support from Omani government for using IT, especially from the ministry of higher education, which is another major reason for carrying out research on IT. This study has selected Dhofar University (DU) as the focal context to study IT adoption. DU has been selected because it is one of the important Universities of Sultanate of Oman.

Additionally, students of DU have come from all the states of the Sultanate of Oman. Moreover, DU is equipped with modern technology and last but not the least, every registered student in DU has two different accounts (outlook account and student information system account). The students can use both accounts within or outside of the campus premises. In addition to this, this study has adopted AUAUT model or carrying out this study with reference to Carter et al (2011) study, which was conducted in USA for testing intentions of using e-file system. The same processes are followed to test the overall impact of the effort and performance expectancy, computer anxiety, social influence, and attitude for the technological usage of information. It helped in analyzing the usage intention of electronic mail system. In this research, following main objective has been strived to achieve:

"To empirically determine if all or any constructs (computer anxiety, social influence, effort expectancy, performance expectancy, and attitude towards technology implementation) have effect on the usage intention of the electronic mail system." 


\section{Literature Background and Research Hypotheses}

\subsection{Information Technology Adoption}

If people perceive that information technology is trustworthy and useful, then, they will have positive attitudes towards its use (Hung et al, 2014). The knowledge of factors behind the information technology adoption presents advantages (Kaba and Touré, 2014). There is different effect of unified theory of information technology acceptance and use, when it is applied to different cultures (Teo and Noyes, 2014).There is a positive relation between attitudes of using information technology and different variables such as self-efficiency, challenges and threats of using information technology as well as previous experience of using computers (Gonen et al, 2014).

There is an important effect of emotional awareness on behavioral issues and beliefs connected with the use of information technology (Guinea et al, 2014). Each one of the cognitive intentions and behavioral outcomes are influenced by different types of factors. On the other hand, cognition is subjected by technological factors, and behavioral outcomes are linked with the social as well as personal factors (Carter et al, 2012). The benefit and expected enjoyment of network may directly and indirectly affect the users' intention of using information technology (Lin and Bhattacherjee, 2008). Selfefficacy of using information technology has been increased with more exposure to technology (Brown, 2012). In general, even if the attitudes are positive to use information technology, some challenges still exist (Pierce and Ball, 2009).

\subsection{Unified Theory of Acceptance and Use of Technology (UTAUT)}

There are different theoretical models, designed to explain users' intention for use and acceptance of the technology, which are based on the sociological and psychological theories. For example, and not as a limitation, innovation diffusion theory IDT (Rogers, 1983),theory of resoned actions TRA (Davis, Bagozzi, \& Warshaw, 1989),technology acceptance model TAM (Davis, 1989), expectancy theory (Thompson, Higgins, \& Howell, 1991), theory of planned behaviour TPB (Taylor \& Todd, 1995), and unified theory of acceptance and use technology UTAUT (Venkatesh, Morris, Davis, \& Davis, 2003). Understanding the users' acceptance and use of IT has been a prominent feature of IT research. UTAUT has been synthesized using eight models of technology use. UTAUT specifically distilled the critical behavioral factors in organizational context; however, it has been implemented to both organizational and non-organizational settings. Although, application as well as replication of the UTAUT model fortifies its generalizability, the model can be extended into three main broad types. The first type is to examine new technologies, in context of health information systems, healthcare consumers and professionals, and new cultural settings.

The second type is for the expansion of the UTAUT scope based on its theoretical mechanism and it is implemented for the addition of new constructs. The third type is integrated for inclusive implementation of the UTAUT variables to identify its exogenous predictors. This application is valuable in developing the understanding of technological integration in the organization within the limits of theoretical boundaries. In this study, third type of UTAUT model expansion has been integrated. Depending on the components of UTAUT model, this study has adopted five constructs and proposed that they may have a major impact on the users' intention to utilize information technology. The factors of social influence, effort expectancy, performance expectancy, computer anxiety, and approach towards technological use have been analyzed. Figure 1 represents the research model, in which every construct being used in the study has been defined.

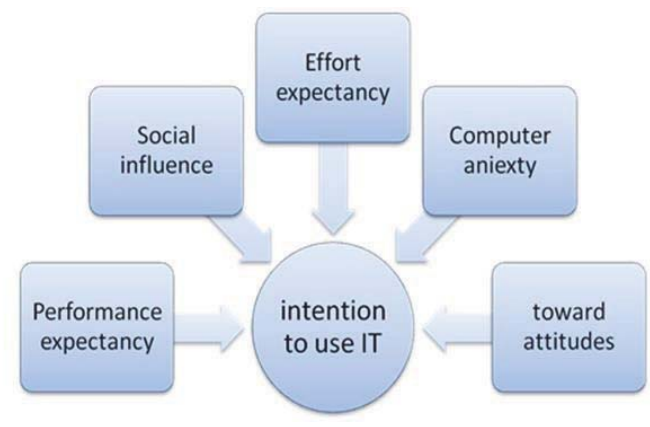

Figure 1: Research Model 


\subsection{Research Hypotheses}

\subsubsection{Performance Expectancy (PE)}

This variable represents the degree to which people may believe that they can use the technology and it may help them in their work performance (Venkatesh et al, 2003). Venkatesh et al (2003) found that performance plays a powerful role to influence the students' intentions for using the e-mail system. Carter et al (2011) found considerable outcomes of performance expectancy on the users' intention for an e-file use. Benbasat and Barki (2007) suggested that the performance expectancy is the stronger factor that can have effect on the information technology adoption. As it relates to e-mail system, students who believe that this system will help them by keeping them in touch with their instructors and administration, then, they will be more likely to use outlook. Thus, the students believe that they will get greater performance outcomes if they use email system because they may require less time and other resources.

$\mathrm{H}_{1}$ : Performance expectancy has significant effect on the students' intention for using e-mail system.

\subsubsection{Effort Expectancy (EE)}

This variable is explained by the extent to which it is ease for the users to associate their experiences with the use of system. In other words, it is referred to ones' awareness of the level of cognitive energy, needed to use the system (Carter et al, 2011). Venkatesh et al (2003) and the studies that reviewed the variable Effort Expectancy, found that the prevalence of this factor is only significant in the initial stages of information technology adoption. Carter et al (2011) examined that the effort expectancy has no positive impact considering the users' intention for the technological adoption. Thus, with regards to e-mail system, students should believe that it is easier to interact with university electronic system.

$\mathrm{H}_{2}$ : Effort expectancy has a major influence on the students' intentions for using e-mailing system.

\subsubsection{Social Influence (SI)}

This variable describes the extent to which one expects that other individuals believe that he should use the new system, specifically individuals who are important to him/her (venkatesh et al, 2003; Carter et al, 2011). Venkatesh et al (2003) found that intention to use new system is affected by social influence. Additionally, the study of Cartar et al (2011) analyzed that the social influence has a dominating factor to assess users' intention for using e-file. The adopter of e-mail system will be more likely to use outlook, if the peers or instructors of the individual have adopted the same technology.

$\mathrm{H}_{3}$ : Social influence has a major effect on the students' intention for using e-mail system.

\subsubsection{Computer Anxiety (CA)}

It is referred as fear or uneasiness, which occurs when someone may use a technology (Simonson et al., 1987). It is revealed that majority of technology users may face anxiety issues within initial periods of using this technology (Ganzel, 1998). The assessment scale for computer anxiety was extended by Heinssen et al (1987). Thus, among the e-mail system students, those having lower degree of computer anxiety will be more likely to adopt information technology.

$\mathrm{H}_{4}$ : Computer anxiety has a major effect on the students' intention for using the e-mail system.

\subsubsection{Attitude towards the Use of Technology ATU}

It is referred as the affective reaction when an individual uses a system. Venkatesh et al (2003) established in their research that the constructs of attitude towards the technological usage is an interesting case. In some studies, the construct of attitude was significant and the strongest predictor of intention, while in other studies, it was found to have no significance. Therefore, Venkatesh et al (2003) considered observing correlation between users' attitude and their intentions for using information technology is spurious.

$\mathrm{H}_{5}$ : Attitude towards the technological usage has a major effect on the students' intention to use outlook.

\section{Methodology}

In order to collect the data, this study has distributed the survey manually to examine participants, who are final year bachelor students at management, accounting and management information systems departments, during the fall 
semester. The goal of the survey questionnaire was to assess the extent to which the participants are aware of the research variables. The results were analyzed using multiple linear regression tests.

\subsection{Sample}

The number of valid questionnairs for analysis was 139. This was completed by the final year students in management, accounting and management information systems departments. $79 \%$ of the respondents were female, respondents' age ranged from 18 - 36. Approximately, $77.7 \%$ of them were within 18-24 age-group. According to the sample distribution majority, which is $41 \%$, belongs to the management information systems and $35.3 \%$ belonged to the accounting department. All students who participated used the Students' Information System through the website of the University. Only $10.8 \%$ of respondents used their own outlook, which was created by university for its own students.

\subsection{Instrument Development}

The distributed survey contain 24 items, were compiled from many validated instruments (venkatesh et al 2003; Carter et al, 2011; Raaij \& Schepers, 2008; Heinssen et al, 1987). This research has made some modifications to fit with the e-mail system content. After that for each construct, randomly, the study has ordered result items. On the survey instrument, the 5-point likert-type is used to measure survey questions, ranging from 1 (strongly disagree) to 5(strongly agree). For reliability, all items were tested using chroubach's alpha (see table 1).

Table (1). Reliability Analysis

\begin{tabular}{|l|c|c|}
\hline Constructs & \# Items & Reliability \\
\hline PE-Performance expectancy & 4 & 0.803 \\
\hline EE-Effort expectancy & 4 & 0.732 \\
\hline SI-Social influence & 5 & 0.715 \\
\hline CA-Computer anxiety & 4 & 0.822 \\
\hline ATU-Attitude toward using technology & 3 & 0.722 \\
\hline USE-Intentions to use of information technology & 4 & 0.716 \\
\hline
\end{tabular}

\section{Analysis of Data}

This study has used multiple linear regression analysis to test our research model. The model is composed of five independent variables (Computer anxiety, Effort expectancy, Social influence, Performance expectancy, and Attitude for the technological use) and one dependent variable (usage intention of information technology). The research aims to determine the extent to which respondents' perception of e-mail system (independent variable) affects their intentions to use the information technology (dependent variable).

\subsection{Results of Study}

Table (2). Multiple Linear Regression Analysis Result

\begin{tabular}{|c|c|c|}
\hline Adjusted R Square & F & Sig. \\
\hline 0.410 & 20.171 & 0.000 \\
\hline
\end{tabular}

Predictors: (Constant), ATU, PE, CA, EE, SI

Dependent Variable: USE

Table (2) is clearly depicting the results of multiple linear regression analysis. The adjusted $\mathrm{R}$ square $=0.41$, which reflects the model interpretation to be $41 \%$ of the variance in students' intention for the adoption of e-mail system. In spite of the whole, model was significant $(F=20.171, P=0.00)$. It is due to the fact that each variable was tested for its individual significance. Depending on this test, only three out of five hypotheses are supported. Table (3) shows the significant and insignificant constructs, as well as supported and unsupported hypotheses. 
Table (3). Hypotheses Test

\begin{tabular}{|c|c|c|c|c|}
\hline Hypotheses & Coefficients & T value & Sig. & Supported \\
\hline H1 (EP) & 0.465 & 6.33 & 0.000 & YES \\
\hline H2 (EE) & 0.231 & 3.14 & 0.002 & YES \\
\hline H3 (SI) & -0.157 & -1.33 & 0.185 & NO \\
\hline H4 (CA) & 0.213 & 3.20 & 0.002 & YES \\
\hline H5 (ATU) & 0.160 & 1.35 & 0.179 & NO \\
\hline
\end{tabular}

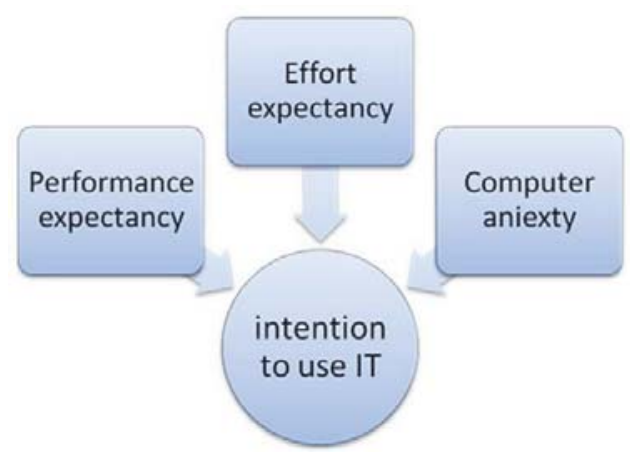

Figure 2: Significant Results

\section{Discussion and Conclusion}

Only three out of five constructs of the adopted model are significant. These three constructs include performance expectancy, effort expectancy, and computer anxiety. It means that the majority of students believed that e-mail system will help them to be in touch with their instructors and administration. Therefore, students will be more likely to use outlook to interact with the university e-mail system, as they believed that it is much easier. Furthermore, it was assumed that they support the idea that students having lower degree of computer anxiety are expected to adopt information technology.

On one hand, the construct attitude toward using technology was not significant and compatible with Venkatesh et al (2003), who considered any observed relationship of users' attitude with their intention for using information technology is spurious. On the other hand, surprisingly social pressure was not significant may be because of the two reasons. Firstly, students prefer to get all information about their study progress through the student information system using their own smart phones. Secondly, there is a culture that students do not trust in electronic transactions. Thus, if they have any transaction, they prefer to use the method of face to face to complete their transaction, personally. Future research should continue to assess the relationship of social influence on the individuals with their IT usage intention, using more focus to culture and trust in electronic transaction.

In this study, the five major constructs (effort expectancy, social influence, computer anxiety, performance expectancy, and user attitude for the technological usage) are used to investigate individuals' perceptions about IT. The study shows that performance expectancy can be considered salient indicator on IT adoption. This construct has helped in explaining the reasons why the students need to adopt the e-mail system. It must be taken into consideration that this study implemented in developed country having small population. So far, the country is in its initial stages of IT adoption. Also, the data was collected using survey, so that there is a potential of self-report bias. For future studies, it is recommended that there should be an attempt to validate the findings of this study by the implementation of its model in different environment. Moreover, all the constructs must also be moderated by other factors like age, gender, culture or by adding new constructs like trust in electronic transactions. However, it is even better to use multiple methods to collect data in the future research studies.

\section{References}

Benbasat, I., and Barki, H. (2007) Quo vadis, TAM?, Journal of the Association for Information Systems, (8:4), pp. 212-218, retrieved 
from http://aisel.aisnet.org/jais/vol8/iss4/16/

Brown, L. J., (2012) Determinants of user adoption of policy and procedure software: An examination of relationships between taskspecific computer self-efficacy, perceived relevance, perceived complexity and predictions of intent to use information technology, Doctoral dissertation - research, Central Michigan University, D.H.A., p. 271, retrieved from http://gradworks.umi. com/35/43/3543988.html

Carter, L., Schaupp, L. C., and McBride, M. E. (2011) The U.S. e-File Initiative: An Investigation of the Antecedents to Adoption from the Individual Taxpayers' Perspective, e-Service Journal, (7:3), pp. 2-19, retrieved from http://www.jstor.org/stable/10.2979/ eservicej.7.3.2

Carter, P. E., Thatcher, J. B., Chudoba, K. M., and Mareit, K. (2012) Post-Acceptance Intentions and Behaviors: An Empirical Investigation of Information Technology Use and Innovation, Journal of Organizational \& End User Computing, (24:1), pp.1-20, retrieved from http://www.igi-global.com/article/post-acceptance-intentions-behaviors/61410

Davis, F. D. (1989). Perceived Usefulness, Perceived Ease of Use, and User Acceptance of Information Technology. MIS Quarterly , 13 (3), 319-340.

Davis, F. D., Bagozzi, R. P., \& Warshaw, P. R. (1989). User Acceptance of Computer Technology: A Comparison of Two Theoretical Models. Management Science, 35 (8), 982-1003.

Fichman, R. G., Dos Santos, B. L., and Zheng, Z. (Eric) (2014) Digital Innovation As A Fundamental And Powerful Concept In The Information Systems Curriculum, MIS Quarterly (38:2), pp. 329-353, retrieved from http://aisel.aisnet.org/cgi/viewcontent.cgi? article $=3171 \&$ context=misq

Ganzel, R. (1998) Feeling squeezed by technology? Training. (35:4), pp. 62-68

Gonen, A., Sharon, D., Offir, A., Lev-Ari, L., (2014) How to enhance nursing students' intention to use information technology: the first step before integrating it in nursing curriculum, Computers, Informatics, Nursing: CIN [Comput Inform Nurs], (32:6), pp. 286-293, retrieved from http://www.ncbi.nlm.nih.gov/pubmed/24784490

Guinea, A. O., Titah, R., and Léger, P. (2014) Explicit and Implicit Antecedents of Users' Behavioral Beliefs in Information Systems: A Neuropsychological Investigation, Journal of Management Information Systems (30:4), pp. 179-209, retrieved from http://www.researchgate.net/publication/257580686_Explicit_and_Implicit_Antecedents_of_Users_Information_Systems_Behavio ral_Beliefs_A_Neuropsychological_Investigation

Heinssen, R.K., Glass, C.R., \& Knight, L.A. (1987) Assessing computer anxiety: Development and validation of the Computer Anxiety Rating Scale, Computers in Human Behavior, 3, pp. 49-59, retrieved from http://www.sciencedirect.com/science/article/pii/ 0747563287900100

Hess,T. J., McNab, A. L., and Basoglu, K. A. (2014) Reliability Generalization Of Perceived Ease Of Use, Perceived Usefulness, And Behavioral Intentions, MIS Quarterly (38:1), pp. 1-28, retrieved from http://misq.org/reliability-generalization-of-perceived-ease-ofuse-perceived-usefulness-and-behavioral-intentions.html

Hung, S, Tsai, J., Chia-An, and Chuang, C. (2014) Investigating primary health care nurses' intention to use information technology: An empirical study in Taiwan, Decision Support Systems, (57), pp. 331-342, retrieved from http://www.sciencedirect.com/science/ article/pii/S0167923613002443

Jasperson, Jon (Sean), Carter, Pamela E. And Zmud, Robert W. (2005) A Comprehensive Conceptualization of Post-Adoptive Behaviors Associated with Information Technology Enabled Work Systems, MIS Quarterly, (29:3), pp. 525-557, retrieved from http://www.jstor.org/discover/10.2307/25148694?uid=3738832\&uid=2\&uid=4\&sid=21106140786351

Kaba, Bangaly, and Touré, Bakary, (2014) Understanding information and communication technology behavioral intention to use: Applying the UTAUT model to social networking site adoption by young people in a least developed country, Journal of the Association for Information Science \& Technology (J ASSOC INF SCI TECHNOL), (65:8), pp. 1662-1674, retrieved from http://onlinelibrary.wiley.com/doi/10.1002/asi.23069/abstract

Lin, C., and Bhattacherjee, A., (2008) Elucidating Individual Intention to Use Interactive Information Technologies: The Role of Network Externalities, International Journal of Electronic Commerce, (13:1), pp. 85-108, retrieved from http://dl.acm.org/citation.cfm?id= 1481749

Pang, M., Tafti, A., and Krishnan, M. S., (2014) Information Technology and Administrative Efficiency In U.S. State Governments: A Stochastic Frontier Approach, MIS Quarterly, (38:4), pp. 1079-1101, retrieved from https://www1.maxwell.syr.edu/uploadedFiles/ conferences/pmrc/Files/Pang_Information\%20Technology\%20and\%20Administrative\%20Efficiency\%20in\%20U.S.\%20State\%20 Governments\%20-\%20A\%20Stochastic\%20Frontier\%20Approach.pdf

Pierce, R., and Ball, L., (2009) Perceptions That May Affect Teachers' Intention to Use Technology in Secondary Mathematics Classes, Educational Studies in Mathematics, (71:3), pp. 299-317, retrieved from http://link.springer.com/article/10.1007\%2Fs10649-0089177-6

Raaij, E. M., and Schepers, J. J.L. (2008) The acceptance and use of a virtual learning environment in China, Computers \& Education (50), pp. 838-852, retrieved from http://www.sciencedirect.com/science/article/pii/S0360131506001382

Rogers, E. M. (1983). diffusion of innovation (3 ed.). New Yourk: The Free Press.

Simonson, Michael R., Maurer, M., Montag-Torardi, M., \& Whitaker, M., (1987) Development of a Standardized Test of Computer Literacy and a Computer Anxiety Index, Journal of Educational Computing Research, (3:2), pp. 231-247, retrieved from http://eric.ed.gov/?id=EJ354389

Taylor, S., \& Todd, P. A. (1995). Understanding Information Technology Usage: A Test of Competing Models. Information Systems Research , 6 (2), 144 - 176. 
Teo, T., and Noyes, J., (2014) Explaining the intention to use technology among pre-service teachers: a multi-group analysis of the Unified Theory of Acceptance and Use of Technology, Interactive Learning Environments, (22:1), pp. 51-66, retrieved from http://www.tandfonline.com/doi/abs/10.1080/10494820.2011.641674

Thompson, R. L., Higgins, C. A., \& Howell, J. M. (1991). Personal Computing: Toward a Conceptual Model of Utilization. MIS Quarterly, 15 (1), 125-143.

Venkatesh, V., Morris, M.G.,Davis, G.B., and Davis, F.D., (2003) User Acceptance of Information Technology: Toward a Unified View, MIS Quarterly, (27: 3), pp. 425-478, retrieved from http://www.jstor.org/discover/10.2307/30036540?uid=3738832\&uid=2\&uid=4 $\&$ sid $=21106140786351$

\section{Appendix 1 - Descriptive Statistics of Survey Items}

\begin{tabular}{|c|c|c|c|c|}
\hline \# & Items & $\mathrm{N}$ & Mean & $\begin{array}{c}\text { Std. } \\
\text { Deviation }\end{array}$ \\
\hline PE1 & Use the outlook will decrease the waste of time. & 139 & 4.0791 & .45148 \\
\hline PE2 & Use the outlook will enhance my effectiveness. & 139 & 4.1367 & .45367 \\
\hline PE3 & Using the outlook makes it easier to track my transactions. & 139 & 4.0432 & .31555 \\
\hline PE4 & I think outlook is useful tool to accomplish my tasks electronically & 139 & 4.0288 & .33928 \\
\hline EE1 & Learning how to use an outlook would be easy for me. & 139 & 4.1439 & .54588 \\
\hline EE2 & For me it would be easy to be skillful at using outlook. & 139 & 4.0863 & .53136 \\
\hline EE3 & I would find the outlook to be flexible to interact with. & 139 & 4.0719 & .54693 \\
\hline EE4 & Overall, I think that the outlook is easy to use. & 139 & 4.2014 & .66135 \\
\hline SI1 & People who influence my behavior think that I have to use outlook. & 139 & 2.3381 & .68687 \\
\hline $\mathrm{SI} 2$ & My peers think that I should use outlook. & 139 & 2.2230 & .43478 \\
\hline SI3 & My supervisor is very supportive for the use of outlook. & 139 & 2.2374 & .57209 \\
\hline $\mathrm{SI} 4$ & I use outlook to accomplish my tasks because of the number of the people around me who use it. & 139 & 2.4101 & .78770 \\
\hline $\mathrm{SI} 5$ & The people that I know who use outlook have more prestige than those who don't do. & 139 & 2.4101 & .85815 \\
\hline CA1 & I feel apprehensive about using outlook to accomplish my tasks. & 139 & 3.9784 & .65350 \\
\hline CA2 & I feel it is difficult to some extent to go through Outlook folders. & 139 & 3.9353 & .66167 \\
\hline CA3 & $\begin{array}{l}\text { I prefer to use other communication channels for the fear of making mistakes I cannot correct when } \\
\text { sending the message. }\end{array}$ & 139 & 3.9712 & .66966 \\
\hline CA4 & I don't like to use EMS for the doubt of receiving my message. & 139 & 3.9424 & .57445 \\
\hline ATU1 & Using the outlook is a good idea. & 139 & 2.3237 & .46959 \\
\hline ATU2 & I have fun using outlook. & 139 & 2.4173 & .71119 \\
\hline ATU3 & The outlook is okay for some tasks but not the kind of tasks I want. & 139 & 2.4748 & .82822 \\
\hline USE1 & I predict that I will use an outlook in the future. & 139 & 4.0935 & .47992 \\
\hline USE2 & Electronic messaging via outlook is something that I would do. & 139 & 4.0863 & .40793 \\
\hline USE3 & I would use the electronic messaging to complete my transactions. & 139 & 4.0576 & .50748 \\
\hline USE4 & I will experiment with an outlook service and then decide whether or not to use it in the future. & 139 & 4.1655 & .51916 \\
\hline $\mathrm{PE}$ & Performance expectancy & 139 & 4.0719 & .31313 \\
\hline EE & Effort expectancy & 139 & 4.1259 & .42709 \\
\hline $\mathrm{SI}$ & Social influence & 139 & 2.3237 & .46836 \\
\hline $\mathrm{CA}$ & Computer anxiety & 139 & 3.9568 & .51774 \\
\hline ATU & Attitude toward using technology & 139 & 2.4053 & .54987 \\
\hline USE & Intention to use & 139 & 4.1007 & .35319 \\
\hline
\end{tabular}

